\title{
Telicitet i dansk og spansk - fra systematiske alternationer til tvetydige strukturer
}

\section{Henrik Høeg Müller \& Antonio Morata}

\begin{abstract}
The aim of this paper is to show how telicity is expressed differently in Danish and Spanish. In the first part, we argue that, in contrast to Danish, Spanish generally does not have the possibility to form antipassives and incorporate bare singular count nouns in object position, and, thus, cannot alternate between a telic and an atelic version of the same verbal expression. This tendency, however, is counterbalanced by the assumption that Spanish transitive structures are often telically ambiguous. In the second part, we suggest that, unlike their translational equivalents in Danish, Spanish telic constructions of the type navegan a/hasta Cádiz 'they sail to Cádiz' - i.e. structures that consist of an unergative activity verb and a directional PP - are systematically ambiguous as to whether the subject referent crosses a boundary. Whether this is the case can only be determined from contextual factors.
\end{abstract}

\section{Nøgleord}

antipassiv, inkorporering, grænsekrydsning, telicitet, tvetydighed

\section{Indledning}

Denne artikel handler om, hvordan telicitet kommer til udtryk på forskellige måder i dansk og spansk, og i et bredere perspektiv, hvordan de germanske og romanske sprog strukturerer begivenheder udtryksmæssigt forskelligt. Omdrejningspunktet for artiklen er den grundindsigt, at mens mange danske verballeksemer generelt set er strukturelt fleksible i den forstand, at de kan projicere forskellige former for transitive og intransitive argumentstruktu- 
rer og dermed referere til begivenheder både som havende et endepunkt, dvs. være teliske, og som ikke havende et endepunkt, dvs. være ateliske, forholder det sig modsat i spansk. Her er mulighederne for grammatiske alternationer som regel relativt begrænsede, og argumentstrukturen synes at forblive uberørt, dog med mulighed for forskellige fortolkninger.

I det følgende afsnit 2 viser vi, at spansk adskiller sig fra dansk ved ikke generelt at have detransitiveringsmekanismer som antipassiv ( $1 \mathrm{a}$ ) og inkorporering af nøgne tællelige substantiver i ental (1b). Dermed kan spansk altså ikke systematisk veksle mellem en telisk og en atelisk version af det samme verbale udtryk, sådan som dansk. Vi argumenterer for, at denne tendens delvist modsvares af, at visse spanske transitive konstruktioner er semantisk underspecificerede mht. telicitet, hvilket medfører, at en enkelt konstruktion i spansk, som leer el periódico i (1c), svarer til flere mere præcise udtryk i dansk (1d).

(1a) sælge osten/ sælge af osten - vender el queso/ * vender del queso

(1b) bygge huset/ bygge hus - construir la casa/*construir casa

(1c) leer el periódico/*leer periódico/ ?leer en el periódico ${ }^{1}$

(1d) læse avisen/ læse avis/ læse i avisen

I afsnit 3 vil vi på baggrund af en korpusanalyse af spanske teliske konstruktioner bestående af et inergativt aktivitetsverbum + PP-retningsadverbial som i (2) nedenfor desuden diskutere den antagelse, at de, modsat deres danske pendanter, er systematisk tvetydige mht., om subjektsreferenten overskrider en grænse eller ej (se fx Aske 1989 og Slobin \& Hoiting 1994 vedr. "boundary-crossing constraint").

Navegan a/hasta Cádiz.

'De sejler til Cádiz.'2

Afsnit 4 indeholder artiklens konklusioner.

1 I leer en el periódico er PP'en et lokativt adverbial, og udtrykket er således stadig transitivt (lese noget $i$ avisen).

2 De spanske eksempler i artiklen oversættes til idiomatisk dansk, men glosseres ikke, idet vi udelukkende fokuserer på, om eksemplerne giver anledning til en telisk eller atelisk læsning. 


\title{
2. Transitive strukturer og grammatiske alternationer
}

Fælles for de to typer af grammatiske alternationer antipassiv og inkorporering er, dels at de som modstykke har den transitive $\mathrm{S}+\mathrm{V}+\mathrm{O}$-struktur, hvor både Agent og Patient udgøres af referentielle størrelser, dels at de intransitiverer den oprindelige transitive struktur - dog på vidt forskellige måder.

\subsection{Antipassiv}

Ifølge Herslund (1996: 218ff.) og Durst-Andersen \& Herslund (1996: 78ff.) består antipassivalternationen $\mathrm{i}$, at Patient-argumentet degraderes og indtager en mere perifer rolle i forhold til prædikationen mellem $\mathrm{S}$ og V, altså stik modsat af passivalternationen, hvor Patient-argumentet jo netop ophøjes til subjekt. Ligeledes ifølge Herslund (1996: 223) medfører denne detransitivering, at

\begin{abstract}
"Situationen fremstilles med subjektsperspektiv, med det intransitive subjekt (Agenten) som involveret i en aktivitet, mens objektet (Patienten) bliver skubbet i baggrunden og derved mister sin prædikatskonstituerende status. Transitive konstruktioner får derved en variant, hvor man i stedet for at udtrykke, at Agenten gør noget ved Patienten udtrykker, at Agenten er involveret i en vis aktivitet; $[\ldots]$ ”.
\end{abstract}

Selv om antipassiv i dansk ikke er grammatikaliseret som morfologisk system og heller ikke eksisterer som mulighed ved alle transitive verber, synes denne valensalternation dog at forekomme ganske systematisk, jf. (3) (se fx Durst-Andersen \& Herslund 1996 for yderligere eksempler).

(3a) Hun læser avisen. - Hun læser i avisen.

(3b) De sælger frugterne. - De sælger af frugterne.

(3c) Han komponerer en symfoni. - Han komponerer på en symfoni.

Denne alternation mellem aktiviteter og handlinger, der i dansk kodes af +/- præposition, kan ikke umiddelbart siges at eksistere i spansk, idet kun et reduceret antal spanske transitive verber efter vores vurdering tillader den præpositionelle, intransitive konstruktion. ${ }^{3}$ Nedenfor i (4) og (5) følger dog nogle eksempler på alternationen.

3 Det skal dog bemærkes, at observationerne vedr. antipassiv ikke bygger på statistiske studier. 
(4a) [...] en México los diferentes gobiernos han combatido los serios problemas en educación, [...]

'[...] i Mexico har de forskellige regeringer (be/ned)kæmpet (mod) alvorlige problemer inden for uddannelse, $[. .$.$] '$

(4b) [...], estudiantes, y obreros han combatido contra los alimentos genéticamente modificados [...]

'[...] studerende og arbejdere har kæmpet mod genetisk modificerede madvarer $[\ldots]$ '

(Müller 2007: 384 [forkortede])

(5a) Entre los tipos de murciélagos que habitan las cuevas hay frugívoros, [...] 'Blandt de typer flagermus, der bebor hulerne, er der frugivore, $[\ldots]$ '

(5b) [...], debido a los animales que habitan en las cuevas.

'[...] pga. de dyr, der bor i hulerne.'

(Müller 2007: 408 [forkortede])

På baggrund af eksempler med de franske verber habiter 'bo i/på, bebo' og pénétrer 'trænge ind, gennemtrænge' anfører Herslund (1996: 228), at den transitive version medfører, at objektsreferenten underkastes verbalhandlingen som en helhed, mens den antipassive ikke har den effekt.

Generelt kan vi konstatere, at både i spansk og fransk har brugen af præposition nogle af de samme semantiske virkninger som i dansk, såsom understregning af aktivitet, fokus på subjektet, nedtoning af objektet og manglende helhedslæsning, men muligheden for at danne disse ateliske prædikater er klart begrænsede i de romanske sprog, og udgør altså ikke et fuldt udviklet system, som det er tilfældet i dansk.

\subsection{Inkorporering}

I lighed med antipassiv kan semantisk inkorporering af det direkte objekt i verbalet ses som en de- eller intransitiveringsproces, hvorved der dannes et atelisk prædikat. I dette tilfælde er der bare ikke tale om, at Patient-rollen degraderes til en syntaktisk mere perifer status, men derimod at $\mathrm{O}$ sammen med $\mathrm{V}$ danner et komplekst intransitivt prædikat, jf. nedenstående fremstilling.

$$
\text { Ole }\left[[\text { maler }]_{\text {simpleksverbum }}[\mathrm{båd}]_{\mathbf{N P}}\right]_{\text {komplekst prædikat }}
$$

I henhold til Dayals (2011) definition af såkaldt pseudo-inkorporering i hindi, som også danner udgangspunkt for analysen af inkorporering af 
nøgne substantiver i objektsposition i dansk hos Müller (2017), gælder det for denne grammatiske alternation, at en nøgen NP, der denoterer en egenskab, inkorporeres under $\mathrm{V}$ som modifikator. ${ }^{4}$ Herved etableres en kompleks enhed, der denoterer en "unitary action" (Dayal 2011: 146), hvor den nøgne NP indsnævrer V's betydning, således at det komplekse prædikat denoterer en undertype af V. Sagt med andre ord dannes prædikatet "at bådmale", som kan udlægges som en særlig form for maleaktivitet. Det nye komplekse prædikat er intransitivt, idet modifikatoren blokerer for $\mathrm{O}$, og samtidig medfører inkorporeringsprocessen en aspektuel kodning af det oprindelige verballeksem som atelisk. Det nye komplekse prædikat denoterer således en aktivitet i stedet for en handling, hvilket fremgår af, at den inkorporerede struktur er kompatibel med ateliske ( $i$ en time) og inkompatibel med teliske adverbialer (på en time), mens det modsatte gælder for den gængse transitive konstruktion, jf. (7a) og (7b).

(7a) Lise læste avis/aviser i en time // \#på en time. ${ }^{5}$

(7b) Lise læste avisen \#i en time // på en time.

(Müller 2017: 52)

Det er dog vigtigt i denne forbindelse at skelne mellem indre og ydre aspekt (se fx Pustejovsky 1991). Kort fortalt angår indre aspekt, hvorvidt det relevante sproglige udtryk indebærer, at objektsreferenten undergår en inkrementel udvikling, dvs. en form for forandring fra et stadium til et andet. Ydre aspekt vedrører derimod muligheden for, at den begivenhed, der denoteres af det pågældende sproglige udtryk, finder sted inden for et afgrænset tidsrum. Dermed er det kun indre aspekt, der har at gøre med telicitet forstået som, at en begivenhed kulminerer i en ny resulterende tilstand. Det indebærer, jf. (8a) og (8b), at inkorporeringsstrukturer rent faktisk godt kan optræde med begge typer af adverbialer.

(8a) Hun vasker bil i fem minutter / / på fem minutter.

(8b) Han børster tænder i fem minutter // på fem minutter.

(Müller 2017: 52)

4 Begrebet pseudo-inkorporering dækker over, at der i modsætning til morfologisk inkorporering ikke finder en formel integration af komponenterne sted, men at de så at sige kun danner en enhed i semantisk forstand.

5 Firkantsymbolet markerer, at sætningen forekommer semantisk anormal. 
Adverbialet på fem minutter indikerer altså blot, at bilvasknings- og tænderbørstningsaktiviteterne foregår inden for fem minutter, men gør ikke i sig selv begivenhederne teliske. At vi så nok i disse konkrete tilfælde alligevel har en tendens til at indlæse en udvikling i objektsreferenterne fra beskidte til rene, må tilskrives pragmatiske årsager. Tilførslen af ydre aspektuelle grænser medfører nemlig ikke nødvendigvis i sig selv en inkrementel fortolkning af objektsreferenten, jf. (9).

(9) Ib nåede både at få spillet violin og set tv på en halv time. (Müller 2017: 53)

Inkorporerede - og for den sags skyld også antipassive - strukturer er altså inhærent ateliske, hvilket den traditionelle adverbialtest ikke entydigt kan afklare.

Den store forskel mellem dansk og spansk mht. inkorporering ligger i, at spansk, med enkelte undtagelser, ikke tillader inkorporering af tællelige substantiver i singularis (Müller 2014). ${ }^{6}$ Til gengæld kan begge sprog inkorporere både pluralis- og massesubstantiver, jf. (10a) og (10b).

(10a) Juan laser avis/skriver brev/maler hus.

'*Juan lee periódico/ *escribe carta/ *pinta casa.'

(10b) Juan plukker kirsebar/ selger cement.

'Juan recoge cerezas/ vende cemento.'

Det betyder, at spansk ikke ved brug af inkorporering kan udtrykke en episodisk (stage-level, jf. Carlson 1977), atelisk enkeltsituation, som i hvad laver Ole? han maler hus?, mens man godt kan give en atelisk permanent individbeskrivelse (individual-level, jf. Carlson ibid.) via inkorporering, som i Ole maler huse - han er husmaler.

\subsection{Spanske transitive strukturers ambiguitet}

Som vi har set, råder spansk altså ikke over de samme grammatiske alternationsmuligheder som dansk inden for det transitive område. Til gen-

6 Spansk tillader inkorporering af nøgne tællelige substantiver i singularis, når der etableres en såkaldt "have-relation" mellem subjekts- og objektsreferent, som i fx Fuan ha comprado coche 'Juan har købt bil' (se Müller 2014 samt referencer deri). 
gæld kan vi konstatere, at en række gængse transitive konstruktioner med referentielt objekt rent faktisk er tvetydige mellem en telisk og en atelisk læsning, jf. (11a) og (11b). ${ }^{7}$

(11a) Juan lee el periódico.

'Juan læser avisen/læser i (en) avis(en).'

(11b) Juan escribe la tesis.

'Juan skriver afhandlingen/skriver på (en) afhandling(en).'

Som oversættelserne til dansk peger på, kan eksemplerne ovenfor både læses som, at subjektsreferenten fx læser et specifikt eksemplar af en avis færdigt eller afslutter skrivningen af en specifik afhandling, men også på den måde, at subjektsreferenten udfører aktiviteten "at læse (i) avis" eller "skrive (på en) afhandling", uden at der egentlig er fokus på en specifik avis eller afhandling. I modsætning hertil vil determinerede objekter i dansk i overvejende grad blive opfattet som deiktiske eller anaforiske, dvs. som referentielle $\mathrm{i}$ traditionel forstand.

Eksemplerne nedenfor i (12a) og (12b) peger ret direkte på en analogi mellem spanske strukturer med determineret direkte objekt og danske strukturer, hvor $\mathrm{O}$ inkorporeres under $\mathrm{V}$ og dermed omdannes til modifikator, jf. analysen beskrevet ovenfor.

\section{Juan ve la tele todo el tiempo.}

'Juan ser fjernsyn hele tiden.'

(12b) Juan siempre toca el piano por la noche.

'Juan spiller altid klaver om aftenen.'

I begge tilfælde er der tale om ateliske prædikater, der udtrykker en aktivitet, og hvor henholdsvis det determinerede objekt i spansk og den nominale modifikator i dansk er kendetegnet ved at være anvendt deskriptivt, dvs. at nominalets funktion, jf. Herslund (2001: 67), er at beskrive eller nævne et begreb uden at forpligte sig på eksistensen af et konkret eksemplar; modsat den referentielle brug, der indebærer, at nominalet forudsættes at eksistere i et givent diskursunivers.

7 Vi gør opmærksom på, at ikke alle konstruktioner af denne type indebærer en tvetydighed, hvorfor der formentlig også er specifikke leksikalske faktorer på spil. Dette perspektiv forfølges dog ikke yderligere her. 
Uden at vi her vil forsøge at definere præcist, om der kan siges at være fuldstændig overensstemmelse mellem nominalernes deskriptive funktion i spansk og dansk i de pågældende konstruktioner, kan vi i hvert fald gå så langt som til på et overordnet plan at konstatere, at spanske transitive strukturer af typen $\mathrm{V}+\mathrm{DET}+\mathrm{NP}$ i visse tilfælde $\mathrm{i}$ en telicitetsmæssig forstand viser funktionel analogi med antipassiv og inkorporering i dansk.

Dermed kan vi helt bredt konkludere, at telicitet indkodes af forskellige typer konstruktioner i dansk og spansk inden for det transitive område forstået som det felt, hvor der optræder et nominal, der på den ene eller den anden måde kan identificeres med en objektsposition.

\section{Intransitive strukturer}

Den mest markante forskel mellem dansk og spansk, og mere generelt de germanske og romanske sprog, inden for det intransitive område er, at spanske inergative bevægelsesverber generelt ikke lader sig konstruere inakkusativt og dermed telisk ved brug af retningspartikler og/eller PPadverbialer, jf. (13) (Aske 1989, Slobin \& Hoiting 1994: 487, Levin \& Rappaport Hovav 1995).

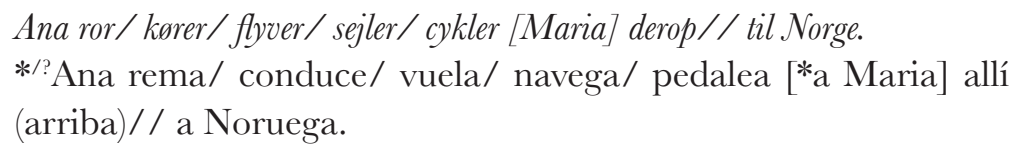
(arriba)// a Noruega.

(Müller 2021)

Herudover er spansk yderligere konstruktionsmæssigt begrænset, idet, som (13) ligeledes peger på, transitivering af aktivitetsverberne er udelukket, eller i hvert fald stærkt indskrænket. Også mulighederne for dannelse af kausative varianter af aktivitetsverber mere generelt, som i han grader lommetorkledet vådt, er reducerede, hvilket, jf. Korzen (2003: 85-89 samt referencer deri), er alment gældende i de romanske sprog.

Spørgsmålstegnet ved de spanske oversættelser i (13) peger imidlertid på, at nogle spanske bevægelsesverber faktisk godt kan konstrueres telisk, hvis deres leksikalske grundbetydning, jf. Pedersen (2010: 181), indebærer en opfattelse af retning, hvilket også de autentiske eksempler (14a) og (14b) viser. Eksemplerne indebærer, at subjektsreferenterne ankommer til nye 
steder, og må derfor betragtes som udtrykkende teliske begivenheder, som i de tilsvarende danske konstruktioner. ${ }^{8}$

(14a) Caminan hasta el Hipódromo por la avenida ancha, solo para mirarlo desde afuera. $^{9}$

'De går hen til væddeløbsbanen ad den brede allé bare for at se på den udefra.'

(14b) [...] porque caminamos a la Catedral donde juntos celebramos la eucaristía [...]

'[...] fordi vi går hen til domkirken, hvor vi holder nadveren sammen $[\ldots]^{\prime}$

Denne mulighed, som i øvrigt synes at gælde mere generelt i de romanske sprog (se fx Herslund 2014: 86-89), vil vi udforske i det følgende med særligt fokus på brugen af a og hasta som de præpositioner, der introducerer de målangivende PP-adverbialer. ${ }^{10}$

\subsection{Graensekrydsning}

Aske (1989: 7) fastslår, at præpositionen hasta "is not telic and doesn't predicate a final location of the Figure, that is, the final location is not asserted, though it certainly may be implied". ${ }^{11}$ Dette argument bruger han til

8 Bemærk, at den spanske præposition $a$ ud over at angive et mål som i (14b), også kan optræde i PP-adverbialer med retningsbetydning, jf. (i).

(i) Cuando los niños caminan a la escuela o a la casa se encuentran con heces.

'Når børnene er på vej i skole eller hjem, støder de på ekskrementer.'

I disse tilfælde er $a$ således betydningsmæssigt ækvivalent med hacia '(hen) mod'.

9 Eksemplerne (14)-(24) kommer fra korpusset NOW (News On the Web), som består af spanske lemmatiserede og annoterede internettekster indsamlet mellem 2012 og 2019. Vores specifikke undersøgelse inkluderer 88 bevægelses- og mådesverber (if. Cifuentes-Férez' inventar fra 2008) bøjet udelukkende i simpel præsens indikativ for at undgå påvirkning fra andre grammatiske kategorier (tempus og aspekt). Ud af dette inventar optræder kun 25 i teliske konstruktioner af den relevante type, og visse af dem med ganske få forekomster, hvilket alt i alt er et udmærket tegn på, at der er tale om et forholdsvist marginalt, om end etableret, fænomen.

10 I spansk eksisterer der en række inakkusative bevægelsesverber såsom entrar/salir og subir/bajar 'bevæge (sig) ind/ud' og 'bevæge (sig) op/ned', som typisk anvendes i beskrivelsen af teliske bevægelsesbegivenheder. Disse verber vil dog ikke blive kommenteret yderligere i artiklen.

11 Aske anvender den kognitiv-semantiske term "Figur", mens vi i artiklen benytter betegnelsen subjektsreferent. 
støtte for den antagelse, at der i spansk findes en særlig telicitetsrestriktion, der vedrører grænsekrydsning. Ifølge Aske er hasta en grænsemarkør, der indikerer, at subjektsreferenten når grænsen til et nyt sted, men intet siger om, at referenten krydser grænsen til og dermed befinder sig dette nye sted. Præpositionen $a$ betragtes til gengæld som en målmarkør af fx Beavers et al. (2010: 347), der præciserer, at "the Spanish preposition $a$ is unacceptable marking goals with manner verbs because it entails boundary crossing". Dette såkaldte "boundary-crossing constraint" (se fx Beavers et al. 2010, Pedersen 2014, blandt mange andre) umuliggør i teorien at kombinere inergative bevægelsesverber med målmarkøren $a$ for at danne en telisk begivenhed og med grænsemarkøren hasta for at indikere grænsekrydsning. Vores analyse viser dog, at billedet er anderledes.

\subsection{Tve- vs. entydighed $i$ spansk og dansk}

Mens spanske $\mathrm{V}_{\text {inerg. }}+\mathrm{PP}$ er tvetydige mht., hvorvidt der krydses en grænse eller ej, gælder det typisk for de tilsvarende danske, at dette forhold ekspliciteres.

$$
\begin{aligned}
& {[\ldots] \text { sin levantar sospechas camina a la calle y busca un taxi para }[\ldots]} \\
& \text { '[...] uden at vække mistanke går hun (ned/ud på vs. hen til) gaden } \\
& \text { og finder en taxa for }[\ldots] \text { ' }
\end{aligned}
$$

Det spanske udtryk camina a la calle specificerer ikke, om subjektsreferenten krydser grænsen til gaden og dermed befinder sig på den, eller om hun blot går hen til gaden, hvorimod man i dansk må eksplicitere, hvilken situation det drejer sig om, jf. retningsangivelserne i parentes. Det samme ville gælde, hvis PP'en var blevet introduceret af hasta. Selvom denne præpositions leksikalske betydning implicerer en fortolkning af PP'en som grænsemarkør svarende til 'hen til' i dansk, ville en fortolkning af grænsekrydsning også være mulig.

Også i spansk er det dog muligt, fx vha. nominalerne el interior/el exterior 'ind i/ud af' som i (16) og (17), sprogligt at præcisere, at grænsekrydsning har fundet sted.

(16) Otro enfermero corre al interior del hospital con un niño de cinco años. 'En anden sygeplejerske løber ind på hospitalet med et 5-årigt barn.'

(17) Isabel corre al exterior del colegio electoral [...]

'Isabel løber ud af valglokalet [...]' 
I det følgende vil vi komme nærmere ind på, hvilke kriterier der skal være opfyldt for, at der i spansk kan dannes en telisk konstruktion af typen $\mathrm{V}_{\text {inerg. }}+\mathrm{PP}$, og hvilke faktorer der har indflydelse på, om subjektsreferenten kan siges at krydse en grænse eller ej. Vi vil argumentere for, at $a$ og hasta i kombination med bevægelsesverber rent faktisk kan udtrykke reel fuldbyrdelse af et mål i form af, at en grænse til en ny lokation definitivt overskrides.

\subsection{Retningsbestemt bevagelse}

Ifølge Pedersen (2010: 189 samt 2014) forholder det sig sådan, at "spanske mådesverber [dvs. inergative aktivitetsverber i betydningen manner verbs] kan forekomme i teliske bevægelseskonstruktioner, hvis der er et element af retningsbestemt bevægelse i verbets leksikalske betydning". Det betyder, at fx bailar 'danse' ikke synes at kunne optræde i de pågældende konstruktioner - hvilket jo ikke er noget problem i dansk, jf. de dansede ud på balkonen - mens der findes relativt mange eksempler med fx correr 'løbe', jf. Pedersen (2010: 179).

At bevægelsen skal være prægnant til stede og kunne retningsbestemmes, kan muligvis også forklare sådan en detalje som, hvorfor vi i NOWkorpusset ikke finder eksempler på verbet merodear 'flakke' anvendt telisk, mens verbet deambular 'slentre' faktisk forekommer én enkelt gang med telisk betydning, jf. (19).

(18) [...] ahora es ofrecida en 800 por los revendedores que merodean a las afueras del inmueble. ${ }^{12}$

'[...] nu bliver det tilbudt til 800 af gadehandlerne, der flakker rundt uden for bygningen.'

(19) [...] jabalies [...] deambulan hasta densas zonas urbanas para buscar alimento en los basureros.

'[...] vildsvin [...] slentrer ned til tætte byområder for at finde føde i skraldespandene.'

Ifølge opslag i DRAE'13 betyder verballeksemet merodear at 'flakke om med lyssky hensigter', hvorved det semantisk nærmer sig acechar 'belure/udspionere', ${ }^{14}$ mens deambular bare refererer til det at bevæge sig rundt uden mål

12 Præpositionen $a$ introducerer her en lokativ PP.

13 Real Academia Españolas ordbog på nettet.

14 Vi takker Susana S. Fernández for denne præcisering. 
for øje. Vi kunne på den baggrund antage, at merodear ikke kan konstrueres telisk, fordi dets bevægelseskomponent er delvist ude af fokus, hvorimod dette ikke gør sig gældende ved deambular, der betydningsmæssigt ligger tæuttere på caminar 'gå'.

Det, at en verbalhandling kan konceptualiseres som en retningsbestemt bevægelse, synes altså at være et grundvilkår for telicitet.

\subsection{Graensens krydsbarhed}

Det første krav til, at en grænse kan krydses, er, at denne grænse giver subjektsreferenten mulighed for at træde ind i et nyt rum, at flytte sig fra et sted til et andet.

(20) Anda hasta su mesa, empuña el arma y dispara cuatro veces a su cabeza. 'Hun går hen til hans bord, tager våbnet i hånden og skyder ham fire gange i hovedet.'

I (20) kan man ikke tale om, at en grænse krydses, da kernen i NP'en su mesa 'hans bord' udgør en endelig lokation, dvs. et mål i sig selv, der ikke åbner adgang til et nyt sted. Subjektsreferenten kan ikke krydse nogen grænse, da der ikke findes nogen ny placering på den anden side, så at sige. Det samme gør sig gældende i følgende eksempel.

Las moscas corretean hasta la pared del tubo de ensayo.

'Fluerne kravler hen til væggen i reagensglasset.'

I dette tilfælde er der heller ikke en grænse at krydse, eftersom målet er siderne på et reagensglas. Hvis PP'en derimod havde været hasta el tubo de ensayo, ville der, jf. tidligere diskussion, være brug for yderligere kontekst for at afgøre, om fluerne nærmer sig reagensglasset, men bliver udenfor (hen til reagensglasset), eller om de nærmer sig for derefter at bevæge sig ind i det (ind i reagensglasset).

\subsection{Agentivitet}

Det ser ud til, at et inagentivt subjekt automatisk medfører en læsning, hvor subjektsreferenten krydser en grænse, jf. (22a-b).

(22a) [...] otra parte [de desechos] se escurre a los ríos o arroyos o se filtra al subsuelo [...]

'[...] en anden del [af affaldet] flyder ned i floderne eller åerne eller siver ned i undergrunden $[\ldots]$ ' 
(22b) El agua se desplaza después a la parte exterior del tambor, donde fluye hasta un tanque de recogida.

'Vandet bevæger sig hen til den ydre del af tromlen, hvor det flyder ind i en opsamlingstank.'

I begge eksempler peger konteksten ret åbenlyst på, at referenterne for de inagentive subjekter, desechos 'affald' og agua 'vand', bevæger sig fra et sted til et andet, men selv uden den udvidede kontekst er det vanskeligt ikke at fortolke basissætningerne som medførende krydsning af en grænse. Man kan sige, at en alternativ læsning nærmest kræver, fx ift. (22b), at der lingvistisk formuleres et ikke passabelt mål (hasta la pared del tanque 'hen til tankens væg'), eller at det ekspliciteres, at grænsekrydsning ikke finder sted (pero se queda fuera 'men det forbliver udenfor').

Et agentivt subjekt synes derimod at have den modsatte effekt. I en række af de eksempler, vi har fundet i korpus, kan a og hasta kun siges at angive ankomst til et mål, ikke krydsning af en grænse, og i tilfælde af, at konteksten giver en forståelse af grænsekrydsning, forholder det sig ofte sådan, at bevægelsen over på den anden side ikke er en del af den aktivitet, der udtrykkes af hovedverbet, jf. (23a-c).

(23a) Muchos tortuguenses navegan a Port-de-Paix [...] en busca de mejor saludo de papeles legales.

'Mange tortugisere [personer fra den haitianske ø Tortuga] sejler til Port-de-Paix [...] på jagt efter bedre levevilkår eller opholdstilladelse.'

(23b) Cuando Segundo Angamarca termina su trabajo en la construcción se apresura hasta su estudio de radio para emitir el programa [...]

'Når Segundo Angamarca er færdig på sit arbejde i byggesektoren, skynder han sig hen til radiostudiet for at sende programmet [...]'

(23c) Marchan al ministerio de Educación para evitar el cierre del Centro de Formación Profesional $\mathcal{N}^{\circ} 414$.

'De marcherer hen til Uddannelsesministeriet for at undgå nedlukningen af erhvervsuddannelsescenter nr. 414.'

Af (23a) fremgår det, at subjektsreferenten ikke bare sejler hen til havnen, men går i land og derved krydser en grænse. Imidlertid foregår grænsekrydsningen ikke ved den aktivitet, som denoteres af verbet navegar 'sejle'. (23b) kan fortolkes på samme måde: Subjektsreferenten iler hen til målet, men eksemplet siger ikke noget om måden, han bevæger sig ind i studiet på, dvs. om det også er med stor hast eller på anden vis. 
I (23c) må det faktisk anses for usandsynligt, at subjektsreferenten marcherer ind i ministeriet, og man kunne argumentere for, at $a$ her i stedet har retningsbetydning, jf. eksemplet i note 8 . I hvert fald står det helt klart, at ønsker man at udtrykke, at aktiviteten foranlediger krydsning af grænsen ind til ministeriet, må det ekspliciteres sprogligt, som i entran marchando 'de bevæger sig ind marcherende' eller marchan al interior 'de marcherer ind i'.

\subsection{Omverdensviden}

Når de enkelte eksempler analyseres med henblik på at afgøre, om de relevante begivenheder indebærer krydsning af en grænse eller ej, hersker der ingen tvivl om, at vi trækker på vores generelle viden om verden. I følgende eksempler spiller vores viden om subjektsreferenten og målet en afgørende rolle.

(24a) [...] estos cetáceos [...] nadan hasta aguas más cálidas del continente americano para aparearse y parir a sus crías.

' $[. .$.$] disse hvaler [...] svømmer ind i de varmere farvande, der$ omgiver det amerikanske kontinent, for at parre sig og føde deres unger.'

(24b) [...] cuando algunos [animales] nadan a tierra firme.

'[...] når nogle [dyr] svømmer ind til land.'

Selv om det sproglige udtryk alene formelt set godt kunne forstås som, at der ikke krydses en grænse, fortolker vi (24a) som, at hvalerne svømmer mod, og også ind i, varmere farvande. Vi ved, at det er målet med deres rejse, og det giver formentlig ikke så meget mening i dette tilfælde at forsøge at fastslå, hvor skillelinjen mellem havmassernes forskellige temperaturer måtte gå.

Eksempel (24b) er tvetydigt, idet det ikke fremgår, hvilken type dyr der refereres til. Vi er derfor ikke i stand til at afgøre, om det drejer sig om landdyr eller amfibier, der svømmer ind mod kysten og derefter bevæger sig videre op på land, eller om der er tale om marine dyr, der svømmer helt ind til kysten, men forbliver $i$ vandet uden at krydse grænsen til land.

Vi ser altså fra forskellige perspektiver, hvordan omverdensviden er vigtig for at kunne afkode eksemplerne og ikke mindst oversætte dem korrekt til dansk, hvor grænsekrydsning eller mangel på samme jo ekspliciteres på den sproglige overflade, og dermed ikke er underspecificeret som i spansk. 


\section{Konklusion}

Vi har i denne artikel vist, at dansk og spansk udtrykker telicitet forskelligt.

De grammatiske alternationer antipassiv og inkorporering, der gør transitive strukturer intransitive og ateliske, er mindre produktive i spansk end $\mathrm{i}$ dansk. Til gengæld kan spanske transitive strukturer med determineret objekt i højere grad end i dansk både læses telisk og atelisk, hvorved der etableres en form for modvægt til de førnævnte alternationers udbredelse i dansk.

Inden for det intransitive område har vi konstateret, at ateliske aktivitetsverber ikke har det samme konstruktionspotentiale i de to sprog. Mens danske $V_{\text {inerg. }}$ systematisk kan gøres teliske ved tilføjelse af en PP, er denne mulighed restringeret i spansk, idet der som minimum kræves, at verbet kan fortolkes som en retningsbestemt bevægelse. På denne bagrund diskuteres, under hvilke betingelser PP'er introduceret af præpositionerne $a$ og hasta er i stand til at generere en telisk læsning, og der fokuseres i særlig grad på deres tvetydighed ift. grænsekrydsning.

Artiklen viser således, at de danske systematiske alternationer af samme verbal i telicitetsregi som regel svarer til en enkelt underspecificeret eller tvetydig konstruktion i spansk. Den spanske argumentstruktur synes at være temmelig grammatisk ufleksibel, dog med mulighed for at skabe flere semantiske fortolkninger. I et typologisk perspektiv harmonerer disse observationer godt med at betragte dansk som et sprog, hvis argumentstruktur er organiseret skematisk, dvs. uafhængigt af verbets leksikalske basisbetydning, mens argumentstrukturen i spansk afhænger af verbets valens, som så kan give anledning til forskellige fortolkninger (se fx Pedersen 2010 og referencer deri).

\section{Om forfatterne}

Henrik Høeg Müller, ph.d., dr.ling.merc., Institut for Kommunikation og - Kultur, Aarhus Universitet.

Antonio Morata, kandidat i lingvistik fra Institut for Kommunikation og - Kultur, Aarhus Universitet.

\section{Litteratur}

Aske, J. (1989): Path predicates in English and Spanish: A closer look. I: Proceedings of the Fifteenth Annual Meeting of the Berkeley Linguistics Society. K. Hall, M. Meacham \& R. Shapiro (red.). Berkeley: Berkeley Linguistics Society, 1-14. 
Beavers, J., B. Levin \& T. Shiao Wei. (2010): The typology of motion expressions revisited. Journal of Linguistics 46(3), 1-58.

Carlson, G.N. (1977): Reference to Kinds in English. Ph.D. thesis. University of Massachusetts. Amherst.

Cifuentes Férez, P. (2008): Motion in English and Spanish: A Perspective from Cognitive Linguistics, Typology and Psycholinguistics. Ph.d.-afhandling. Universidad de Murcia.

Corpus del Español. M. Davies. Http://www.corpusdelespanol.org

Dayal, V. (2011): Hindi pseudo-incorporation. Natural Language E̊ Linguistic Theory 29(1), 123-167.

Durst-Andersen, P. \& M. Herslund (1996): The syntax of Danish verbs: Lexical and syntactic transitivity. I: Content, Expression and Structure. Studies in Danish functional grammar. E. Engberg-Pedersen et al. (red.). Amsterdam: Benjamins, 65-102.

Herslund, M. (red.). (1996): Det franske sprog. Kapitel III. Valens og transitivitet. CBS.

Herslund, M. (2001): Modality and the Indefinite Article. I: Reflections on Modality. H.H. Müller (red.). Copenhagen Studies in Laguage 26, 67-80.

Herslund, M. (2014): Mouvement et déplacement. Typologie des verbes de mouvement en roman et en germanique. I: Between Romance and Germanic: Language, Text, Cognition and Culture. I. Korzen, A. Ferrari \& A-M. De Cesare (red.). Bern: Peter Lang, 75-94.

Korzen, H. (2003): Attribut de L'object t valence dérivée. Étude contrastive dano-française. I: Aspects Linguistiques de la Traduction. M. Herslund (red.). Bordeaux: Presses Universitaires de Bordeaux. 85-102.

Levin, B. \& M. Rappaport Hovav (1995): Unaccusativity: At the Syntax-Lexical Semantics Interface. Cambridge, Mass.: The MIT Press.

Müller, H.H. (2007): Nominalkomposition i moderne spansk. En teori om betydningsdannelse. Disputats. CBS.

Müller, H.H. (2014): Lexical Coding vs. Syntactic Marking of Homogeneity. Evidence from Spanish and Danish. Studies in Language 38(4), 896-955.

Müller, H.H. (2017): Bare Nouns in Danish with special reference to the object position. Nordic Journal of Linguistics 40(1), 37-72.

Müller, H.H. (2021): Complementarity and division of labor between endo- and exocentric languages. The case of Danish and Spanish. Globe 12, 4-17.

Pedersen, J. (2010): Marginal brug af mådesverber i spanske bevægelsesudtryk. Typologisk status. I: Ny Forskning $i$ Grammatik 17. M. Birkelund, 
L. Dam, H. Dam-Jensen \& S.S. Fernández (red.). Odense: Syddansk Universitet, 167-194.

Pedersen, J. (2014): Variable type framing in Spanish constructions of directed motion. I: Romance perspectives on Construction Grammar. H. Boas \& F. Gonzálvez-García (red.). Amsterdam: John Benjamins, 269-305.

Pustejovsky, J. (1991): The generative lexicon. Computational Linguistics 17, 409-441.

Slobin, D.I. \& N. Hoiting. (1994): Reference to movement in spoken and signed languages: typological considerations. I: Proceedings of the Twentieth Annual Meeting of the Berkeley Linguistic Society. S. Gahl, A. Dolbey \& G. Johnson (red.). Berkeley: Berkeley Linguistics Society, 487-505. 